\title{
Exposure to polycyclic aromatic hydrocarbons among never smokers in Golestan Province, Iran, an area of high incidence of esophageal cancer - a cross-sectional study with repeated measurement of urinary 1-OHPG in two
}

\section{seasons}

\section{Farhad Islami 1,2,3 *, Paolo Boffetta ${ }^{4,5}$, Frederik J. van Schooten ${ }^{6}$, Paul Strickland $^{7}$, David H. Phillips ${ }^{8}$, Akram Pourshams ${ }^{2}$, Akbar Fazel-Tabar Malekshah ${ }^{2}$, Roger Godschalk ${ }^{6}$, Elham Jafari ${ }^{2}$, Arash Etemadi ${ }^{2,9}$, Salahadin Abubaker ${ }^{7}$, Farin Kamangar ${ }^{9}$, Kurt Straif ${ }^{1}$, Henrik Møller ${ }^{3}$, Joachim Schüz ${ }^{1}$ and Reza Malekzadeh ${ }^{2}$ *}

1 International Agency for Research on Cancer, Lyon, France

${ }^{2}$ Digestive Disease Research Center, Shariati Hospital, Tehran University of Medical Sciences, Tehran, Iran

${ }^{3}$ King's College London, Thames Cancer Registry, London, UK

${ }^{4}$ International Prevention Research Institute, Lyon, France

${ }^{5}$ The Tisch Cancer Institute and Institute for Transitional Epidemiology, Mount Sinai School of Medicine, New York, NY, USA

${ }^{6}$ Department of Toxicology, NUTRIM, Maastricht University, Maastricht, Netherlands

${ }^{7}$ Department of Epidemiology, Bloomberg School of Public Health, Johns Hopkins University, Baltimore, MD, USA

${ }^{8}$ Section of Molecular Carcinogenesis, Institute of Cancer Research, Sutton, UK

${ }^{9}$ Division of Cancer Epidemiology and Genetics, National Cancer Institute, National Institutes of Health, Bethesda, MD, USA

\section{Edited by:}

Roel Vermeulen, Utrecht University, Netherlands

Reviewed by:

Michael Blaise Cook, National Cancer Institute, USA

David Michael DeMarini, U.S.

Environmental Protection Agency, USA

\section{*Correspondence:}

Farhad Islami, International Agency for Research on Cancer, 150 Cours Albert Thomas, 69008 Lyon, France. e-mail: farhad.islami@mssm.edu; Reza Malekzadeh, Digestive Disease Research Center, Tehran University of Medical Sciences, Shariati Hospital, Kargar Shomali Avenue, 14117 Tehran, Iran.

e-mail:malek@ams.ac.ir
Studies have suggested a possible role of polycyclic aromatic hydrocarbons (PAHs) in the etiology of esophageal cancer in Golestan Province, Iran, where incidence of this cancer is very high. In order to investigate the patterns of non-smoking related exposure to PAHs in Golestan, we conducted a cross-sectional study collecting questionnaire data, genotyping polymorphisms related to PAH metabolism, and measuring levels of 1-hydroxypyrene glucuronide (1-OHPG), a PAH metabolite, in urine samples collected in two seasons from the same group of 111 randomly selected never-smoking women. Beta-coefficients for correlations between 1-OHPG as dependent variable and other variables were calculated using linear regression models. The creatinine-adjusted 1-OHPG levels in both winter and summer samples were approximately $110 \mu \mathrm{mol} / \mathrm{mol} \mathrm{Cr}(P$ for seasonal difference $=0.40)$. In winter, red meat intake $(\beta=0.208 ; P=0.03)$, processed meat intake $(\beta=0.218 ; P=0.02)$, and GSTT1-02 polymorphism ("null" genotype: $\beta=0.228 ; P=0.02$ ) showed associations with 1-OHPG levels, while CYP1B1-07 polymorphism (GG versus AA+GA genotypes: $\beta=-0.256 ; P=0.008$ ) showed an inverse association. In summer, making bread at home ( $>$ weekly versus never: $\beta=0.203 ; P=0.04$ ), second-hand smoke (exposure to $\geq 3$ cigarettes versus no exposure: $\beta=0.254 ; P=0.01$ ), and GSTM1-02 "null" genotype ( $\beta=0.198$; $P=0.04$ ) showed associations with 1-OHPG levels, but GSTP1-02 polymorphism (CT + TT versus CC: $\beta=-0.218 ; P=0.03$ ) showed an inverse association. This study confirms high exposure of the general population in Golestan to PAHs and suggests that certain foods, cooking methods, and genetic polymorphisms increase exposure to PAHs.

Keywords: 1-hydroxypyrene glucuronide, esophageal cancer, frying, red meat, polycyclic aromatic hydrocarbon, polymorphism

\section{INTRODUCTION}

Polycyclic aromatic hydrocarbons (PAHs) are by-products of incomplete combustion of organic matter and occur as mixtures of complex and variable composition. The major sources of PAHs are tobacco smoking, some occupational exposures (such as coke oven working), air pollution, and diet, particularly charbroiled or fried foods (Unwin et al., 2006; Perello et al., 2008; Kamangar et al., 2009). The International Agency for Research on Cancer has classified benzo $[a]$ pyrene, a prototype $\mathrm{PAH}$, and exposures in several occupations with heavy exposure to PAHs as carcinogenic to humans (Baan et al., 2009). Consistent associations between those occupational exposures and cancers of the lung and skin have been shown in epidemiological studies, and strong mechanistic evidence and carcinogenicity in several animal species has been reported for benzo[ $a$ ] pyrene (Baan et al., 2009). An association between PAHs and urinary bladder has also been reported in 
several studies (Bosetti et al., 2007). Factors such as the route of exposure, the chemical composition of the mixture, the presence of co-exposures, and genetic susceptibility are likely to explain interorgan differences in the carcinogenicity of PAH (IARC Working Group, 2010).

Cross-sectional studies in high-incidence areas of esophageal squamous cell carcinoma (ESCC) in Linxian (China) and Golestan Province (Iran) indicate that the inhabitants of these areas are highly exposed to PAHs (Roth et al., 1998a,b, 2001; Wornat et al., 2001; Kamangar et al., 2005; Islami et al., 2009b). The hypothesis of a carcinogenic role of $\mathrm{PAH}$ on the esophageal mucosa is supported by experimental and epidemiological studies, including those showing an increased risk of ESCC among chimney sweeps (Hogstedt et al., 1982; Evanoff et al., 1993) and tobacco smokers (Hecht, 2003). We have recently reported in a case-control study in Golestan Province higher levels of antibodies against benzo[a]pyrene diol epoxide-I-modified guanosine in non-tumoral esophageal biopsies from patients with biopsy-proven ESCC than in biopsies from control subjects (Abedi-Ardekani et al., 2010).

In Golestan Province, where both ESCC rates and exposure to PAHs are high, the sources of exposure to PAHs are not well characterized. High PAH exposure levels (compared to several other populations; see Discussion) in Golestan have been observed among non-smokers as well as smokers, and only $15 \%$ of the variance in PAH levels in urine was accounted for by known factors, such as age, sex, place of residence (rural versus urban), and tobacco use (Kamangar et al., 2005). We conducted an exploratory molecular epidemiological study on healthy, never-smoking female inhabitants of Golestan Province to investigate the patterns of exposure to PAHs, sources of PAHs other than tobacco smoking, and the association of several lifestyle and genetic factors with 1hydroxypyrene glucuronide (1-OHPG) levels in urine. 1-OHPG is a stable PAH metabolite that reflects recent (within the past $24 \mathrm{~h}$ ) exposure to mixed PAHs (Roth et al., 2001). The half-life for urinary excretion of 1-OHPG ranges from 6 to $35 \mathrm{~h}$ and peak urine concentration occurs a few hours following exposure (Strickland et al., 1996).

\section{MATERIALS AND METHODS STUDY SUBJECTS}

For this study, 111 participants in the Golestan Cohort Study were randomly selected. The Golestan Cohort Study is a prospective study that recruited 50,045 participants, 40-75 years of age, from eastern parts of Golestan Province between January 2004 and June 2008, with 40,013 participants from 326 villages and 10,032 from urban areas (Pourshams et al., 2010). In order to investigate sources of PAHs other than tobacco smoking, specifically potential exposure from cooking methods, only never-smoking women were enrolled in this study because preparation of food in the area is usually done by women, so they might provide more precise information about food consumption and cooking methods. Furthermore, smoking among women in Golestan is uncommon; therefore, erroneous assignment of tobacco use is less likely among women. Also, if exposure to PAHs is to be a major cause of ESCC in Golestan, this should be true in both men and women, as incidence of ESCC is high in both sexes. The age adjusted incidence rates (ASR) for ESCC in men and women in Golestan are 43 and 36 per $10^{5}$ person-years, respectively (Semnani et al., 2006), with higher rates in eastern than in western parts of the province (Mahboubi et al., 1973). The overall ASR for esophageal cancer among men and women in the more developed areas of the world is 6.5 and 1.2 per $10^{5}$ person-years, respectively; the respective rates in the less developed areas are 11.8 and 5.7 (Jemal et al., 2011). An earlier study did not show any difference by sex in 1-OHPG levels in urine samples in Golestan (Kamangar et al., 2005).

\section{DATA AND BIOLOGICAL SAMPLE COLLECTION}

Data and biological sample collection from all participants took place in two rounds: one from December 2006 to January 2007 (hereafter referred to as the winter round) and the other from August to early September 2007 (the summer round). In the winter round, information on demographic characteristics and duration of using a heating system (in hours) during the previous 24-h and the fuel used for heating was collected from all participants. All food and beverage items consumed the previous day were recorded on an open questionnaire. Height and weight of participants were also measured by trained research staff. Questionnaire data on exposure to second-hand smoke and cooking practice were collected in both rounds. We asked questions about exposure to second-hand smoke in general and over the previous $24 \mathrm{~h}$, and in case of any exposure, the numbers of cigarettes of second-hand smoke per day was recorded. We asked study participant whether they did cooking in general and over the previous $24-\mathrm{h}$, and when the reply was positive, cooking frequency was recorded. We also collected data on cooking methods in the household, including frying, boiling, baking, and barbecuing in general (and not over the previous $24 \mathrm{~h}$ ), as well as frying intensity, which was assessed by questioning the change in foods' color caused by frying. For this, we proposed four options: no frying, little change in color, becoming golden, and becoming brown or darkening. For our analyses, the first two categories were considered as no/little frying and the third and fourth categories were combined and considered as high-temperature frying.

In order to obtain repeated urine samples in two seasons, in both winter and summer rounds a single spot urine sample was collected from each participant and stored at $-20^{\circ} \mathrm{C}$. In the winter round, $10 \mathrm{ml}$ of peripheral venous blood was collected in EDTA containing tubes. Buffy coat containing white blood cells were obtained and stored at $-70^{\circ} \mathrm{C}$ until genotyping. All biological samples were collected in mornings or early afternoons during weekdays. In both seasons, questionnaire data and biological samples were collected from each participant on the same day. The study was reviewed and approved by the Institutional Review Board of the Digestive Disease Research Center of Tehran University of Medical Sciences. Informed written consent was obtained from all participants.

\section{LABORATORY ASSESSMENTS}

Details of the laboratory assessments are available in the Section "Appendix." Briefly, 1-OHPG concentration was measured in 4.5$\mathrm{ml}$ spot urine specimens at the Department of Environmental Health Sciences, Johns Hopkins Bloomberg School of Public Health, Baltimore, United States, using the assay developed by 
Strickland et al. (1994). This was done with synchronous fluorescence spectroscopy (Perkin Elmer LS50B Luminescence spectrometer, Norwalk, CT, USA) using a wavelength difference of $34 \mathrm{~nm}$ between excitation and emission. The limit of detection was $0.01 \mathrm{ng} 1-\mathrm{OHPG} / \mathrm{ml}$ urine and the recovery of the assay was 95-100\%. Fourteen control samples were used to assess the reliability of 1-OHPG measurements. With the mean of $5.74 \mathrm{pmol} / \mathrm{ml}$ (SD: 0.64 ), the coefficient of variation was $11.1 \%$.

Genotyping was performed at the Department of Health Risk Analysis and Toxicology, Maastricht University, Maastricht, the Netherlands. Genetic variants including single nucleotide polymorphisms (SNPs) or deletions in the following genes were determined: genes for phase I metabolizing enzymes myeloperoxidase (MPO) and cytochromes P450s (CYP1A1, CYP1A2, CYP1B1, $C Y P 2 E 1$, and $C Y P 3 A 4)$ and for phase II metabolizing enzymes glutathione $S$-transferases (GSTM1, GSTP1, GSTT1), and Nacetyltransferase 2 (NAT2). Details of the primer development are available elsewhere (Knaapen et al., 2004; Ketelslegers et al., 2006). Genotyping was performed by the single base extension (SBE) method using SnaPShot (Applied Biosystems, Nieuwerkerk, a.d. Ijssel, the Netherlands), and primer 3 and Netprimer software were used to design SBE primers (Knaapen et al., 2004; Ketelslegers et al., 2006; Langie et al., 2010). Finally, the samples were analyzed on an ABI Prism 3100 genetic analyser using Genescan Analysis software. Polymerase chain reaction (PCR) primers were designed using Primer 3 and Netprimer software. More detailed information about the studied genetic variants and genotyping is presented in the Section "Appendix."

\section{STATISTICAL ANALYSIS}

Food recall data over the previous $24 \mathrm{~h}$ were transformed to specific food group intake values. Intake of food groups was categorized into two groups, as below median and equal to or above median. When medians included zero, the intakes were categorized as no intake and any intake. Intake of red meat $(\geq$ median versus $<$ median) showed an association with 1-OHPG level in preliminary analyses, so it was examined in further analyses as a continuous variable (log-transformed), as well as a categorical variable with three groups. Nearly half of the participants did not consume red meat over the previous $24 \mathrm{~h}$, so they were included in one group and those who ate red meat were categorized in two equal-sized groups according to their intake. For the continuous variable, a constant value of 0.1 was added to red meat intake values before log-transformation.

The normality of the 1-OHPG variable distributions was assessed by histograms and the Shapiro-Wilk $W$ test, and the distributions were found to be severely skewed. With logtransformation, the distribution became normal, so we used logtransformed 1-OHPG values in all further analyses. Creatinine (Cr)-adjusted 1-OHPG levels in winter and summer samples, from participants with paired samples only $(n=106)$, were compared using paired $t$-tests. Linear regression models were used to investigate the association between Cr-adjusted 1-OHPG level and variables of interest. Categorical results from genotyping were treated as follows: the wild-type homozygote group was categorized as the reference genotype and coded as 0 (zero), the heterozygote group was coded as 1 , and the homozygote variant group was coded as
2. Results from the summer round were adjusted for age (continuous), place of residence (urban; rural), ethnicity (non-Turkmen; Turkmen), body mass index (BMI, $\mathrm{kg} / \mathrm{m}^{2}$, log-transformed), and frequency of second-hand smoke exposure over the previous $24 \mathrm{~h}$ (none; $1-2 ; \geq 3$ cigarettes/day). Results from the winter round were additionally adjusted for red meat (none; $1-24 ; \geq 25$ ) and processed meat (no use, some use) consumption over the previous $24 \mathrm{~h}$. For all linear regression models, we report regression coefficients and $P$-values (two-sided) to illustrate the associations. For categorical variables with more than two categories, $P$-values for trend were obtained from adjusted regression models by assigning consecutive numbers to categories within each variable.

\section{RESULTS}

\section{1-OHPG LEVELS, OVERALL AND IN ASSOCIATION WITH DEMOGRAPHIC FACTORS AND BODY MASS INDEX}

Table 1 shows median levels of 1-OHPG and creatinine, and median and 25th and 75th percentiles of Cr-adjusted 1-OHPG in urine samples by demographic characteristics. 1-OHPG levels in urine were obtained for 108 participants in winter and 109 participants in summer. Overall, the median 1-OHPG level in summer was 2.5 -fold higher than the median level in winter. On the other hand, the creatinine levels in summer were approximately twice as high as in winter, indicating that urine samples collected in winter were more diluted than the summer urine samples. Therefore, the Cr-adjusted 1-OHPG level did not show a seasonal difference $(P=0.40)$; levels in both winter and summer samples were approximately $110 \mu \mathrm{mol} / \mathrm{molCr}$. For each of the categories of demographic variables, Cr-adjusted 1-OHPG levels in summer and winter were not significantly different. Cr-adjusted 1-OHPG levels in the urban area seemed to be the same in summer and winter $(0.110$ and $0.111 \mu \mathrm{mol} / \mathrm{molCr}$, respectively; $P=0.68)$. The median level in rural areas changed from $0.105 \mu \mathrm{mol} / \mathrm{molCr}$ in winter to $0.136 \mu \mathrm{mol} / \mathrm{molCr}$ in summer $(P=0.46)$. Approximately $68 \%$ of participants used natural gas for heating in winter; $32 \%$ used kerosene. There was no association between 1-OHPG levels in urine and fuels used for heating or duration of using heating systems over the previous $24 \mathrm{~h}$ (data not shown).

There was no major variation in Cr-adjusted 1-OHPG levels by different categories of age, place of residence, ethnicity, and education (Table 2). There was an association between $\mathrm{Cr}$ adjusted 1-OHPG in winter and BMI ( $P$ for trend $=0.03$ ), but the association was disappeared after adjustments for other factors. Cr-adjusted 1-OHPG level in summer was not associated with BMI.

\section{1-OHPG LEVELS AND FOOD INTAKE}

Food intake data were available only for the winter round of the study. Table 3 shows the relation between Cr-adjusted 1-OHPG levels in urine and intake of selected food groups over the previous $24 \mathrm{~h}$. Intake of red meat and processed meat were associated with 1-OHPG levels. Regression coefficient was $0.208(P=0.03)$ for red meat and $0.218(P=0.02)$ for processed meat consumption; however, only $2.9 \%$ of participants consumed processed meat over the previous $24 \mathrm{~h}$. Regression coefficient for intake of fat was -0.191 $(P=0.06)$. The coefficients for other food groups were smaller than the above values. 
Table 1 | Creatinine and 1-OHPG levels in urine in relation to demographic characteristics ${ }^{\mathrm{a}}$.

\begin{tabular}{|c|c|c|c|c|c|c|c|c|}
\hline \multirow{2}{*}{$\begin{array}{l}\text { Demographic } \\
\text { characteristics }\end{array}$} & \multirow[b]{2}{*}{ No. $(\%)$} & \multicolumn{3}{|c|}{ Winter } & \multicolumn{3}{|c|}{ Summer } & \multirow{2}{*}{$\begin{array}{l}P \text { for } \\
\text { seasonal diff. }^{b}\end{array}$} \\
\hline & & $\begin{array}{l}\text { Median } \\
\text { 1-OHPG }\end{array}$ & $\begin{array}{l}\text { Median } \\
\mathrm{Cr}\end{array}$ & $\begin{array}{l}\text { Median Cr-adjusted } \\
\text { 1-OHPG (p25, p75) }\end{array}$ & $\begin{array}{l}\text { Median } \\
\text { 1-OHPG }\end{array}$ & $\begin{array}{l}\text { Median } \\
\mathrm{Cr}\end{array}$ & $\begin{array}{l}\text { Median Cr-adjusted } \\
\text { 1-OHPG (p25, p75) }\end{array}$ & \\
\hline All participants & $111(100)$ & 1.03 & 121.2 & $0.107(0.057,0.166)$ & 2.54 & 243.7 & $0.113(0.047,0.242)$ & 0.40 \\
\hline \multicolumn{9}{|l|}{ AGE } \\
\hline \multicolumn{9}{|c|}{ PLACE OF RESIDENCE } \\
\hline Urban & $44(39.6)$ & 1.24 & 128.1 & $0.110(0.058,1.171)$ & 2.16 & 234.8 & $0.111(0.047,0.228)$ & 0.68 \\
\hline Rural & $67(60.4)$ & 0.98 & 97.0 & $0.105(0.056,0.161)$ & 2.70 & 246.8 & $0.136(0.046,0.254)$ & 0.46 \\
\hline \multicolumn{9}{|l|}{ ETHNICITY } \\
\hline Non-Turkmen & $24(21.6)$ & 0.91 & 158.4 & $0.080(0.045,0.136)$ & 1.63 & 223.7 & $0.086(0.043,0.179)$ & 0.67 \\
\hline
\end{tabular}

a-OHPG levels in urine were obtained from 108 participants in winter and 109 participants in summer. The biomarker levels are presented in following units: 1-OHPG, pmol/ml; creatinine, $\mathrm{mg} / \mathrm{dl}$; creatinine-adjusted 1-OHPG, $\mu \mathrm{mol} / \mathrm{mol} \mathrm{Cr}$

${ }^{b} P$-value for difference in Cr-adjusted 1-OHPG levels in winter and summer (in logarithmic scale), calculated using paired t-tests. The number of participant with paired results was 106.

1-OHPG, 1-hydroxypyrene glucuronide; $\mathrm{Cr}$, creatinine.

Table 2 | Crude and adjusted beta-coefficients and $\boldsymbol{P}$-values for the association of demographic characteristics and body mass index with creatinine-adjusted 1-hydroxypyrene glucuronide levels in urine ${ }^{a}$.

\begin{tabular}{|c|c|c|c|c|c|c|c|c|c|c|}
\hline \multirow[t]{2}{*}{ Characteristics } & \multicolumn{6}{|c|}{ Winter } & \multicolumn{4}{|c|}{ Summer } \\
\hline & Crude $\beta$ & $\boldsymbol{P}$ & Adjusted $\beta 1$ & $\boldsymbol{P}$ & Adjusted $\beta 2$ & $\boldsymbol{P}$ & Crude $\beta$ & $\boldsymbol{P}$ & Adjusted $\beta 1$ & $\boldsymbol{P}$ \\
\hline \multicolumn{11}{|l|}{ PLACE OF RESIDENCE } \\
\hline Urban & Reference & - & Reference & - & Reference & - & Reference & - & Reference & - \\
\hline Rural & -0.035 & 0.72 & -0.121 & 0.29 & -0.111 & 0.32 & 0.034 & 0.73 & -0.037 & 0.74 \\
\hline Non-Turkmen & Reference & - & Reference & - & Reference & - & Reference & - & Reference & - \\
\hline Turkmen & 0.084 & 0.39 & 0.137 & 0.25 & 0.115 & 0.32 & 0.077 & 0.43 & 0.098 & 0.38 \\
\hline \multicolumn{11}{|l|}{ EDUCATION } \\
\hline No school & Reference & - & Reference & - & Reference & - & Reference & - & Reference & - \\
\hline Some school & -0.021 & 0.83 & -0.029 & 0.82 & 0.032 & 0.79 & -0.060 & 0.53 & -0.089 & 0.45 \\
\hline Body mass index $\left(\mathrm{kg} / \mathrm{m}^{2}\right)^{b}$ & 0.213 & 0.03 & 0.132 & 0.20 & 0.130 & 0.19 & -0.037 & 0.70 & -0.006 & 0.96 \\
\hline
\end{tabular}

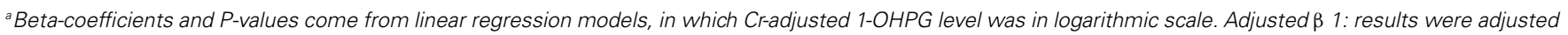
for other variables listed in the table and frequency of second-hand smoke exposure over the previous $24 \mathrm{~h}$ (none; $1-2 ; \geq 3$ cigarettes/day) in the respective season. Adjusted $\beta$ 2: results from winter were additionally adjusted for red meat (none; 1-24; $\geq 25 \mathrm{~g}$ ) and processed meat (no use, any use) consumption over the previous $24 \mathrm{~h}$.

${ }^{b}$ Mean (SD).

\section{1-OHPG LEVELS AND SECOND-HAND SMOKING}

Exposure to second-hand tobacco smoke from three or more cigarettes over the previous $24 \mathrm{~h}$ compared to those who were not exposed to tobacco smoke (Table 4) was associated with increased levels of 1-OHPG; this was stronger in summer $(\beta=0.254 ; P=0.008)$ than in winter $(\beta=0.156 ; P=0.12)$. The coefficient for the correlation between 1-OHPG levels and exposure to second-hand smoke from one or two cigarettes was -0.019 in winter $(P=0.86)$ and -0.152 in summer $(P=0.13)$ 
Table 3 | Crude and adjusted beta-coefficients and $\boldsymbol{P}$-values for the association between intake of selected food groups (over the previous $24 \mathrm{~h}$ ) and creatinine-adjusted 1-OHPG levels in urine in winter ${ }^{a}$.

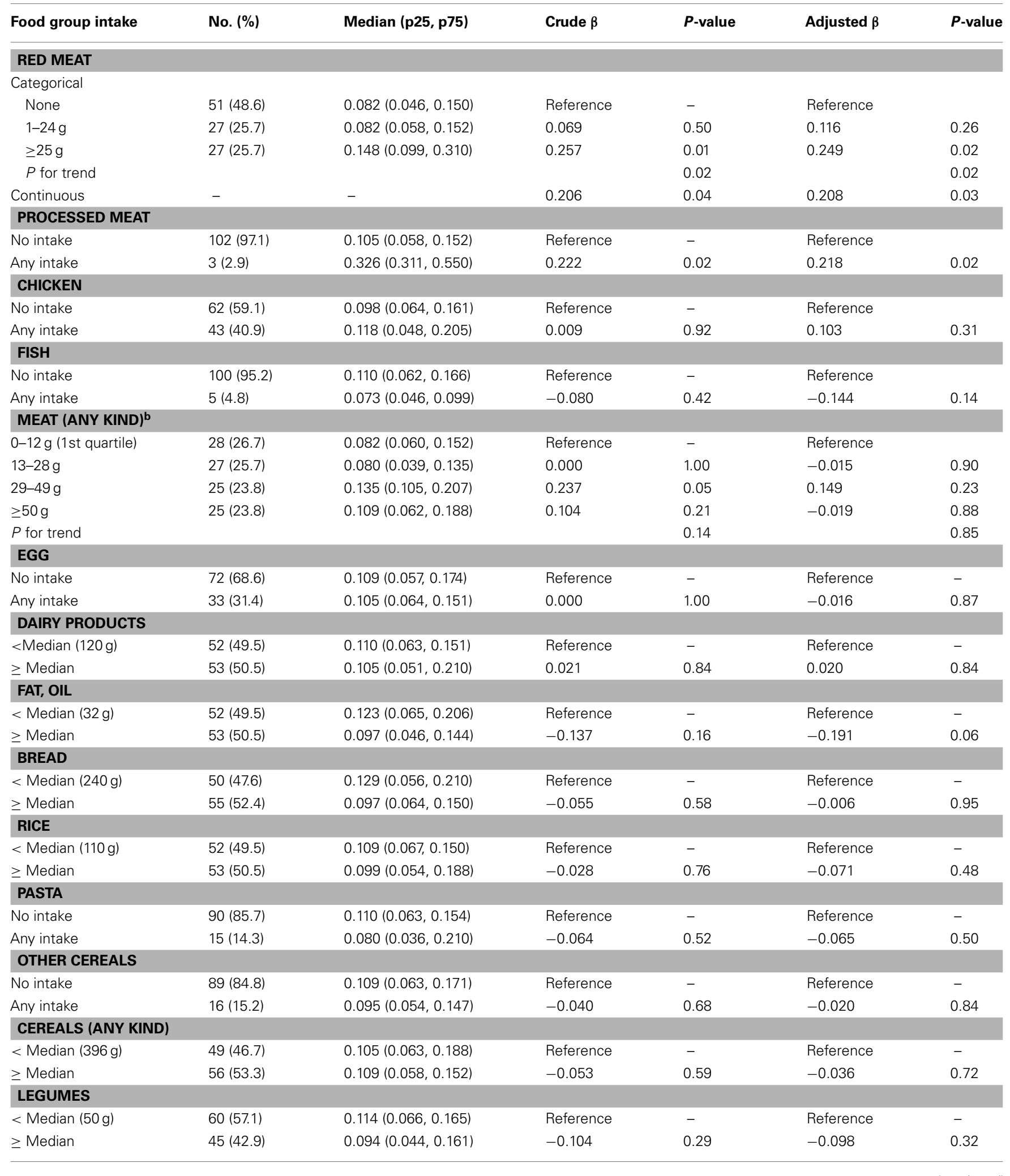


Table 3 | continued

\begin{tabular}{|c|c|c|c|c|c|c|}
\hline Food group intake & No. (\%) & Median (p25, p75) & Crude $\beta$ & $P$-value & Adjusted $\beta$ & $\boldsymbol{P}$-value \\
\hline \multicolumn{7}{|l|}{ VEGETABLES } \\
\hline$<$ Median (93 g) & $52(49.5)$ & $0.107(0.060,0.174)$ & Reference & - & Reference & - \\
\hline \multicolumn{7}{|l|}{ FRUIT } \\
\hline No intake & $61(58.1)$ & $0.131(0.067,0.207)$ & Reference & - & Reference & - \\
\hline No intake & $86(81.9)$ & $0.110(0.062,0.161)$ & Reference & - & Reference & - \\
\hline Any intake & $19(18.1)$ & $0.091(0.039,0.210)$ & -0.078 & 0.43 & 0.044 & 0.66 \\
\hline \multicolumn{7}{|l|}{ PICKLES } \\
\hline No intake & $83(79.0)$ & $0.113(0.058,0.152)$ & Reference & - & Reference & - \\
\hline Any intake & $22(30.0)$ & $0.078(0.063,0.210)$ & -0.037 & 0.71 & -0.108 & 0.28 \\
\hline \multicolumn{7}{|c|}{ SWEETS, SWEET DRINKS } \\
\hline
\end{tabular}

${ }^{a}$ Median and 25 th and 75 th percentiles of 1-OHPG are presented in $\mu$ mol/molCr. Beta-coefficients and P-values come from linear regression models, in which creatinine-adjusted 1-OHPG level in logarithmic scale was the dependent variable. Adjusted models included age (continuous), place of residence (urban; rural), ethnicity (non-Turkmen; Turkmen), body mass index ( $\mathrm{kg} / \mathrm{m}^{2}$, logarithmic scale), frequency of exposure to second-hand smoke over the previous 24h (none; 1-2; $\geq 3$ cigarettes/day) and red meat (none; $1-24 ; \geq 25 \mathrm{~g}$ ) and processed meat (no use, any use) consumption over the previous $24 \mathrm{~h}$

${ }^{b}$ Including red meat, processed meat, chicken, and fish.

1-OHPG, 1-hydroxypyrene glucuronide; Cr, creatinine.

\section{1-OHPG LEVELS AND COOKING PRACTICES}

Table 4 also shows the relation between Cr-adjusted 1-OHPG levels in urine, making bread at home and the intensity of food frying. Making bread at home more than once a week in summer was associated with increased 1-OHPG $(\beta=0.203 ; P=0.04) ; P$ for trend was 0.04 . Such an association was not observed in winter. With regard to frying intensity, the strongest positive correlations were observed with high-temperature frying of red meat $(\beta=0.144$; $P=0.15)$ and onion $(\beta=0.126 ; P=0.20)$ in winter. There was an inverse association between high-temperature frying of vegetables and 1-OHPG levels in summer $(\beta=-0.223 ; P=0.03)$. There was no association between 1-OHPG level in urine and several other variables related to food preparing (data not shown), including cooking over the previous day or regular cooking in general, cooking rice, boiling the food groups presented in Table 4, and fuels used for baking bread or preparing foods. Nearly all of the participants used natural gas for baking or cooking. Whereas hightemperature frying was a common cooking practice (Table 4), barbecuing was uncommon and had no association with 1-OHPG levels (data not shown).

\section{1-OHPG LEVELS AND GENOTYPES}

Table 5 shows the distribution of the studied genotypes, $P$-value for Hardy-Weinberg equilibrium for each gene, and the relation between Cr-adjusted 1-OHPG levels in winter and the genotypes. A few genes were not in Hardy-Weinberg equilibrium; none of them had an association with 1-OHPG levels. The pattern of association were generally different in the winter and summer rounds. However, relatively consistent results were found for the GT + TT (versus GG) genotypes of CYP2E1-05, which showed fairly strong inverse association with $1-\mathrm{OHPG}$ levels in winter $(\beta=-0.176$;
$P=0.07)$ and summer $(\beta=-0.184 ; P=0.07)$. In winter, the " $n u l l$ " genotype of GSTT1-02 was associated with increased 1-OHPG levels $(\beta=0.228 ; P=0.02)$, while there were inverse associations for GG genotype (versus AA + GA genotypes) of CYP1B1-07 $(\beta=-$ $0.256 ; P=0.008)$. In summer, the CT + TT genotype of GSTP1-02 $(\beta=-0.218 ; P=0.03)$ showed an inverse and the "null" genotype of GSTM1-02 $(\beta=0.198 ; P=0.04)$ showed a positive association with 1-OHPG levels.

\section{DISCUSSION}

This study showed similar levels of a urinary biomarker of PAH exposure in summer and winter. Red and processed meat intake and GSTT1-02 polymorphism showed correlations with 1-OHPG levels in winter, while CYP1B1-07 polymorphism had an inverse correlation. In summer, making bread at home, second-hand smoke, and GSTM1-02 polymorphism were correlated with 1OHPG levels, but GSTP1-02 polymorphism showed an inverse association; food intake data were not available for this season.

Participants in the current study, who were all female nonsmokers, had higher 1-OHPG levels compared to non-smokers without occupational exposure to PAHs in several other studies that used the same methodology as this study for assessing 1-OHPG; in fact, the levels in this study were comparable to those of smokers in the other studies (Table 6). The higher SD for Cr-adjusted 1-OHPG levels in the current study suggests that inter-individual variability is larger in our study participants than in other populations. Almost all of the participants in the current study used natural gas or kerosene for heating in winter. The similarity of the Cr-adjusted 1-OHPG levels in summer and winter implies that exposure to PAHs through heating in winter does not have a major effect on total exposure in Golestan. As we used 
Table 4 | Crude and adjusted Beta-coefficients and $\boldsymbol{P}$-values for the association of second-hand smoke exposure (over the previous $24 \mathrm{~h}$ ), frying intensity, and several genetic factors with creatinine-adjusted 1-hydroxypyrene glucuronide levels in urine ${ }^{\mathrm{a}}$.

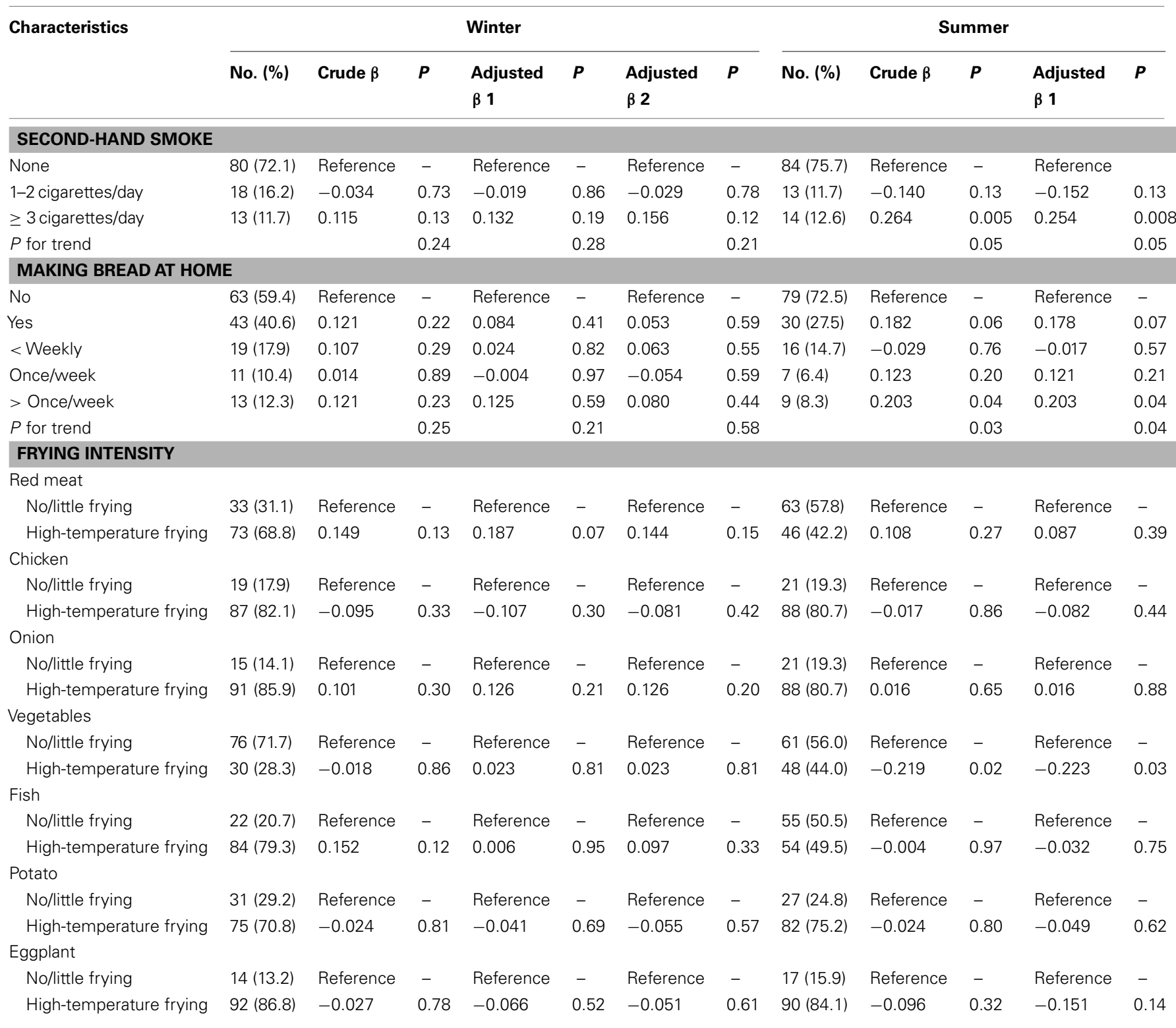

${ }^{a}$ Beta-coefficients and P-values come from linear regression models, in which creatinine (Cr)-adjusted 1-OHPG level in logarithmic scale was the dependent variable. Adjusted $\beta$ 1: results were adjusted for age (continuous), place of residence (urban; rural), ethnicity (non-Turkmen; Turkmen), body mass index (kg/ $\mathrm{m}^{2}$, logarithmic scale), and frequency of exposure to second-hand smoke over the previous $24 \mathrm{~h}$ (none; $1-2 ; \geq 3$ cigarettes/day) in the respective season. Adjusted $\beta 2$ : results from winter were additionally adjusted for red meat (none; $1-24 ; \geq 25 \mathrm{~g}$ ) and processed meat (no use, any use) consumption over the previous 24-h.

paired $t$-tests, any substantial overall intra-individual variability in the two seasons is unlikely. In concordance with this finding, the fuels used for heating and the duration of their use did not show any association with 1-OHPG levels.

Diet seems to be the main source of PAHs among non-smokers who do not have occupational exposure to those compounds in studies from other regions of the world (Straif et al., 2005). However, information on the role of diet in exposure to PAHs in Golestan is limited. Only two earlier studies in Golestan have investigated such association. These studies assessed the PAH levels in commonly eaten foods and in bread and rice (the two major staple foods in the region), but they did not find high levels on average (Joint Iran-IARC Study Group, 1977; Hakami et al., 2008). In one of those studies, however, when the daily intake of benzo $[a]$ pyrene was estimated from its levels in cooked rice, bread, and drinking water, the daily intake of the compound in Golestan was higher than in a low-risk area in Iran (Hakami et al., 2008). In the current study, participants were questioned about the frying intensity of the consumed food in general rather than over the previous $24 \mathrm{~h}$. 1-OHPG levels in urine reflect recent exposure (within hours) to 


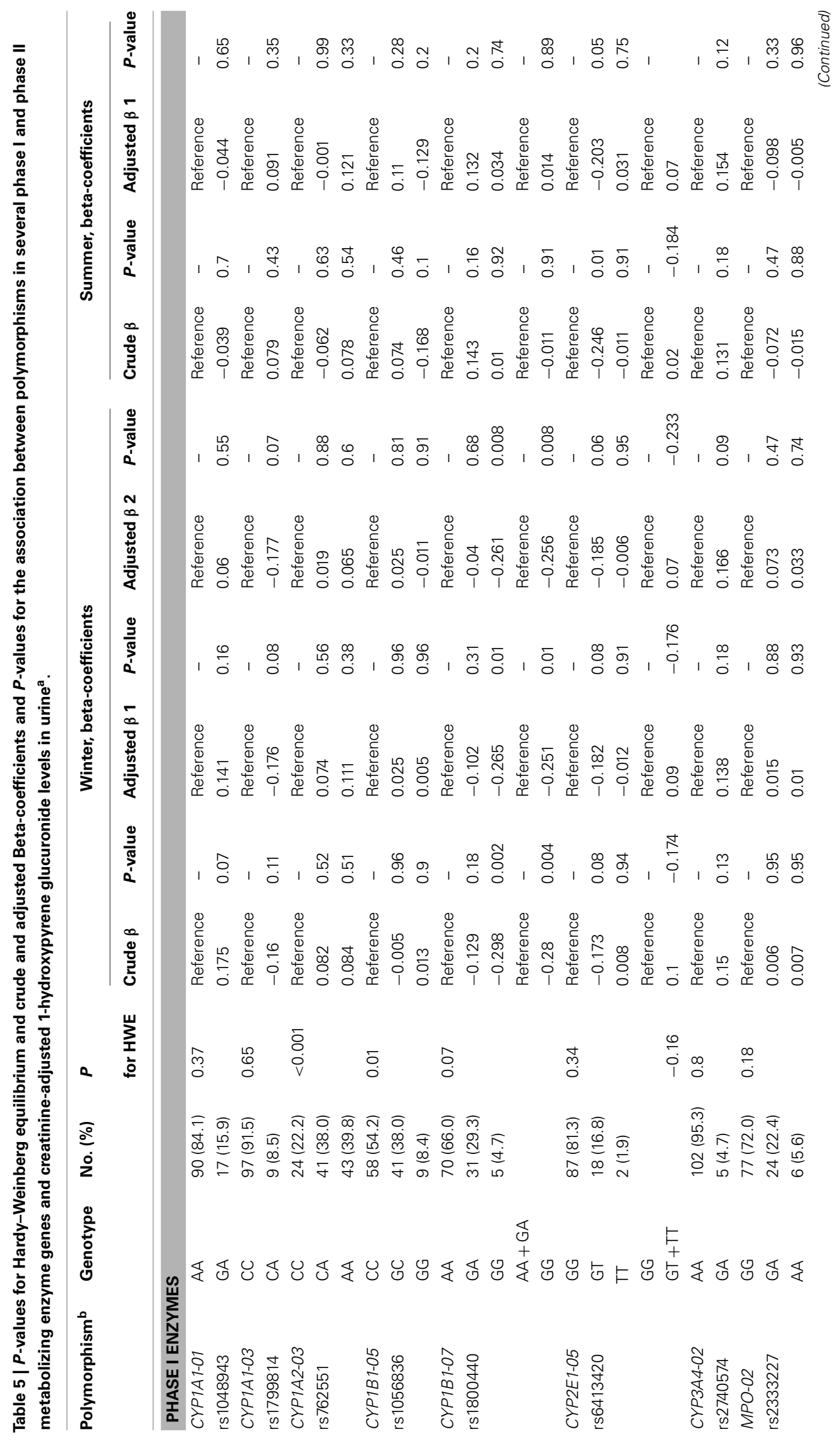




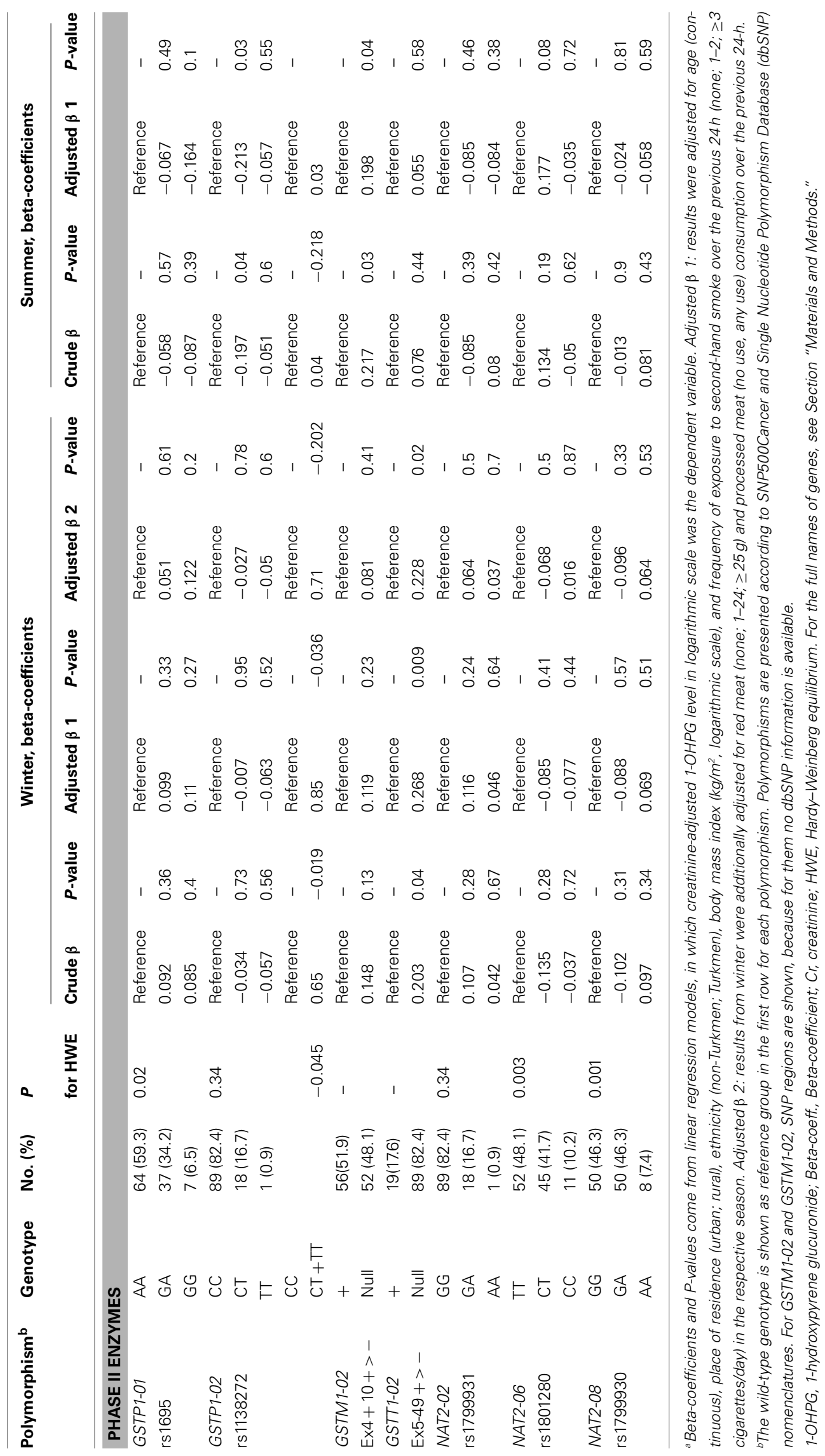


Table 6 | Examples of 1-OHPG levels assessed with the same methodology in different studies ${ }^{\text {a }}$.

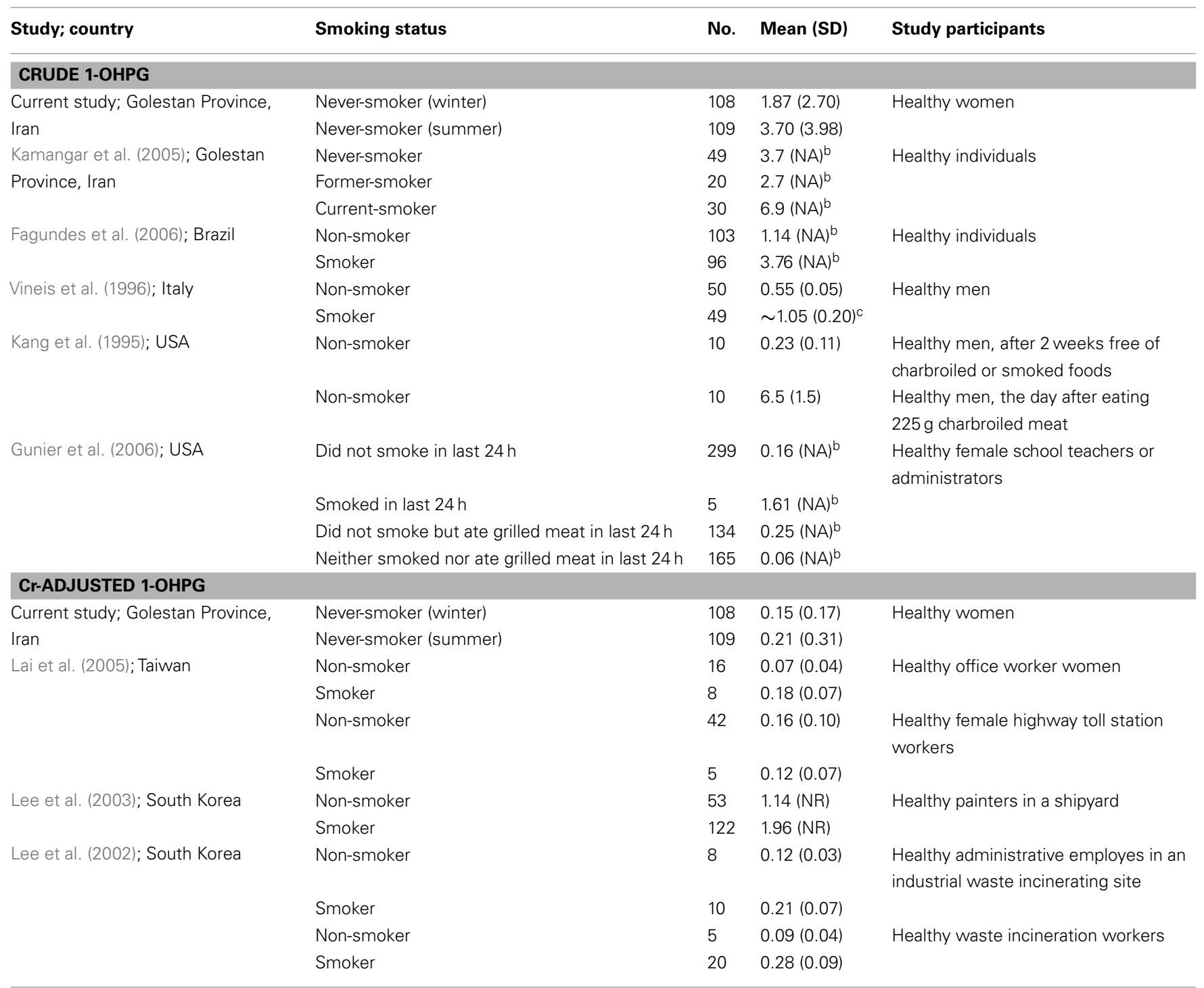

${ }^{a}$ Crude 1-OHPG and Cradjusted 1-OHPG levels are presented in pmol/m/ urine and mol/molCr, respectively.

${ }^{b}$ Medians were presented.

'Smokers were divided to two groups; 1-OHPG level was 1.0 (SD 0.15) in flue-cured tobacco users ( $n=31)$ and 1.1 (SD 0.23$)$ in air-cured tobacco smokers ( $n=16)$ 1-OHPG, 1-hydroxypyrene glucuronide; Cr, creatinine; NA, not applicable; NR, not reported.

PAHs, so the level may not be an optimal indicator of exposure to PAHs from fried food in general rather than in the previous few hours. This fact and also the association between red meat intake and 1-OHPG level suggests that fried red meat may be an important source of PAH among those who use this food in Golestan, although the association for fried red meat did not reach statistical significance in our study. Frying has been shown to increase the PAH content of foods; for example, in a study in Spain, the total PAH content of raw lamb increased from $5.5 \mu \mathrm{g} / \mathrm{kg}$ fresh weight to $16.9 \mu \mathrm{g} / \mathrm{kg}$ after frying (Perello et al., 2008). In our study, the association between BMI and 1-OHPG level in winter may be related to food intake, because the association was disappeared following adjustments for other factors, including red meat intake.
Making bread at home in summer showed an association with 1-OHPG levels. On the other hand, there was no association between 1-OHPG and making bread at home in winter. The fuel used for making bread in both seasons was natural gas, so it is not clear why such a practice was associated with increased exposure to PAHs in only one round of our study. Some possible explanations may be that the association is due to chance or that making bread at home is a proxy for another habit or practice which is associated with higher exposure to PAHs in summer than in winter.

Only a limited number of studies have investigated the association between second-hand smoke and PAHs or their metabolites in urine (Scherer et al., 1992; Suwan-Ampai et al., 2009). A recent large study reported that elevated urinary concentrations of most 
PAH metabolites are associated with exposure to second-hand smoke (Suwan-Ampai et al., 2009). Our findings also suggest a similar association in both seasons, although the association in winter was weaker than in summer. Our small sample size may be one of the reasons for not observing a statistically significant association in winter. There was no increase in 1-OHPG levels with exposure to tobacco smoke from one or two cigarettes; this amount of exposure might not be sufficient to increase 1-OHPG levels in urine.

Phase I enzymes in the metabolic pathways of PAHs, including CYPs and MPO, usually catalyze PAHs to more reactive metabolites. Phase II enzymes, such as GSTs, catalyze the conjugation of PAHs or their reactive metabolites to compounds that are more water-soluble, so that they are more readily excreted (Chen et al., 2007). Several studies have investigated the association between polymorphisms in genes encoding the above enzymes and levels of PAH metabolites in urine, but the results have not been very consistent (Alexandrie et al., 2000; Schoket et al., 2001; Apostoli et al., 2003; Abnet et al., 2007; Chen et al., 2007; Chuang and Chang, 2007; Petchpoung et al., 2011). In our study, polymorphisms in some CYP genes were associated with lower levels of 1-OHPG, while deletions in GSTM1 and GSTT1 were associated with elevated levels. However, except for CYP2E1-05, the other polymorphisms did not show a consistent pattern in winter and summer. The significance and repeatability of these findings need to be examined in further studies.

While the Caspian Littoral region in general is a humid area, the areas with highest incidence of ESCC in Golestan have a relatively dry climate (Mahboubi, 1971). The urine samples collected in winter were more diluted than summer urine, which may be related to greater dehydration of inhabitants in Golestan in summer than in winter. From a methodological point of view, this suggests the importance of adjustment for creatinine levels when a single spot urine sample is analyzed for PAH metabolites. Different patterns of association in the winter and summer rounds in our study, e.g., with regard to BMI, suggest exposure to different sources of PAH in different seasons in Golestan. These potential variations should also be considered in future investigations.

Our study has strengths and limitations. We collected extensive questionnaire data, which allowed us to examine the associations of interest while considering the influence of several other lifestylerelated factors. We collected samples in two seasons to reduce the effect of inter-individual and seasonal variations. However, not having 24 -h food intake data in the second round (summer) did not allow us to compare the pattern of exposure to PAHs in the two seasons with regard to diet and to adjust the analyses in the summer for diet. Furthermore, multiple comparisons were done in

\section{REFERENCES}

Abedi-Ardekani, B., Kamangar, F., Hewitt, S. M., Hainaut, P., Sotoudeh, M., Abnet, C. C., Taylor, P. R., Boffetta, P., Malekzadeh, R., and Dawsey, S. M. (2010). Polycyclic aromatic hydrocarbon exposure in oesophageal tissue and risk of oesophageal squamous cell carcinoma in north-eastern Iran. Gut 59, 1178-1183.

Abnet, C. C., Fagundes, R. B., Strickland, P. T., Kamangar, F., Roth, M. J., Taylor, P. R., and Dawsey, S. M. (2007). The influence of genetic polymorphisms in Ahr, CYP1A1, CYP1A2, CYP1B1, GST M1, GST T1 and UGT1A1 on urine

our analyses. Therefore, some of the statistically significant results might have arisen by chance. However, at least regarding exposure to red meat intake, the results seem to be robust.

In summary, the study confirms high exposure to PAHs of the general population in Golestan, which does not seem to be related to heating in winter, and for which certain foods may be important factors among individuals who consume those foods. With regard to esophageal cancer, it is possible that drinking hot tea, a habit common in Golestan, exposes esophageal cells to higher amounts of ingested PAHs than in individuals who drink their tea at moderate temperatures (Islami et al., 2009a,c). Exposure to second-hand tobacco smoke also showed an association with PAHs, but the prevalence of the exposure was low. Although hightemperature frying is a common cooking practice in Golestan, approximately $50 \%$ of participants in our study did not consume red meat in the previous $24 \mathrm{~h}$. We were not able to identify the factors explaining the high levels of PAH in all participants, suggesting that there is no single factor responsible for this pattern in our study population and, very likely, in Golestan. The potential differences in pattern of exposure in summer and winter also points to variability of major sources of PAHs. Results of this pilot study may be helpful in determining the issues to be focused on in future studies, e.g., PAH content in fried foods and potential seasonal variation in sources of PAHs. Further studies on biomarkers of internal exposure (e.g., PAH-related DNA adducts) and on the potential association of exposure to PAHs and risk of esophageal cancer are also warranted. Due to possible associations of exposure to ingested PAHs with several other health outcomes, including cancer of the urinary bladder and cardiovascular diseases (Curfs et al., 2005; Ramos and Moorthy, 2005; Baan et al., 2009), the benefits of identifying and avoiding the preventable exposures to PAHs in the general population may go beyond esophageal cancer.

\section{ACKNOWLEDGMENTS}

We thank interviewers and laboratory technicians of the Golestan Cohort Study and also Ms. Goharshad Goglani from Digestive Disease Research Center for her logistic assistance. We are grateful to Francois Deloche from International Agency for Research on Cancer for his assistance in arrangement and transfer of samples. Funding: Data and sample collection was supported by Digestive Disease Research Center of Tehran University of Medical Sciences and International Agency for Research on Cancer. Laboratory assessments were funded by ECNIS (Environmental Cancer Risk, Nutrition and Individual Susceptibility), a network of excellence operating within the European Union 6th Framework Program [Priority 5: "Food Quality and Safety" (Contract No. 513943)].

1-hydroxypyrene glucuronide concentrations in healthy subjects from Rio Grande do Sul, Brazil. Carcinogenesis 28, 112-117.

Alexandrie, A. K., Warholm, M. Carstensen, U., Axmon, A., Hagmar, L., Levin, J. O., Ostman, C., and Rannug, A. (2000). CYP1Al and GSTM1 polymorphisms affect urinary 1-hydroxypyrene levels after $\mathrm{PAH}$ exposure. Carcinogenesis 21, 669-676.

Apostoli, P., Neri, G., Lucas, D., Manno, M., and Berthou, F. (2003). Influence of genetic polymorphisms of CYP1A1 and GSTM1 on the urinary levels of 1-hydroxypyrene. Toxicol. Lett. 144, 27-34. 
Baan, R., Grosse, Y., Straif, K., Secretan, B., El Ghissassi, F., Bouvard, V., Benbrahim-Tallaa, L., Guha, N., Freeman, C., Galichet, L., and Cogliano, V. (2009). A review of human carcinogens - Part F: chemical agents and related occupations. Lancet Oncol. 10, 1143-1144.

Bosetti, C., Boffetta, P., and La, V. C. (2007). Occupational exposures to polycyclic aromatic hydrocarbons, and respiratory and urinary tract cancers: a quantitative review to 2005. Ann. Oncol. 18, 431-446.

Chen, B., Hu, Y., Jin, T., Lu, D., Shao, M., Zheng, L., Wang, Q., Shen, Y., Liu, H., Liu, Y., and Zhou, Y. (2007). The influence of metabolic gene polymorphisms on urinary 1-hydroxypyrene concentrations in Chinese coke oven workers. Sci. Total Environ. 381, 38-46.

Chuang, C. Y., and Chang, C. C. (2007). Urinary 1-hydroxypyrene level relative to vehicle exhaust exposure mediated by metabolic enzyme polymorphisms. J. Occup. Health 49, 140-151.

Curfs, D. M., Knaapen, A. M., Pachen, D. M., Gijbels, M. J., Lutgens, E., Smook, M. L., Kockx, M. M., Daemen, M. J., and van Schooten, F. J. (2005). Polycyclic aromatic hydrocarbons induce an inflammatory atherosclerotic plaque phenotype irrespective of their DNA binding properties. FASEB J. 19, 1290-1292.

Evanoff, B. A., Gustavsson, P., and Hogstedt, C. (1993). Mortality and incidence of cancer in a cohort of Swedish chimney sweeps: an extended follow up study. Br. J. Ind. Med. 50, 450-459.

Fagundes, R. B., Abnet, C. C., Strickland, P. T., Kamangar, F., Roth, M. J., Taylor, P. R., and Dawsey, S. M. (2006). Higher urine 1hydroxy pyrene glucuronide (1OHPG) is associated with tobacco smoke exposure and drinking mate in healthy subjects from Rio Grande do Sul, Brazil. BMC Cancer 6, 139. doi:10.1186/1471-2407-6-139

Gunier, R. B., Reynolds, P., Hurley, S. E., Yerabati, S., Hertz, A., Strickland, P., and Horn-Ross, P. L. (2006). Estimating exposure to polycyclic aromatic hydrocarbons: a comparison of survey, biological monitoring, and geographic information system-based methods. Cancer Epidemiol. Biomarkers Prev. 15, 1376-1381.

Hakami, R., Mohtadinia, J., Etemadi, A., Kamangar, F., Nemati, M., Pourshams, A., Islami, F., Nasrollahzadeh, D., Saberi-Firoozi, M., Birkett, N., Boffetta, P., and Malekzadeh, R. (2008). Dietary intake of benzo(a)pyrene and risk of esophageal cancer in North of Iran. Nutr. Cancer 60, 216-221.

Hecht, S. S. (2003). Tobacco carcinogens, their biomarkers and tobaccoinduced cancer. Nat. Rev. Cancer 3, 733-744.

Hogstedt, C., Andersson, K., Frenning, B., and Gustavsson, A. (1982). A cohort study on mortality among long-time employed Swedish chimney sweeps. Scand. J. Work Environ. Health 8(Suppl. 1), 72-78.

IARC Working Group. (2010). Some Non-Heterocyclic Polycyclic Aromatic Hydrocarbons and Some Related Exposures. IARC Monographs on the Evaluation of Carcinogenic Risks to Humans, Vol. 92. Lyon: IARC Press.

Islami, F., Boffetta, P., Ren, J. S., Pedoeim, L., Khatib, D., and Kamangar, F. (2009a). Hightemperature beverages and foods and esophageal cancer risk-A systematic review. Int. J. Cancer 125 , 491-524.

Islami, F., Kamangar, F., Nasrollahzadeh, D., Moller, H., Boffetta, P., and Malekzadeh, R. (2009b). Oesophageal cancer in Golestan Province, a high-incidence area in northern Iran - A review. Eur. J. Cancer 45, 3156-3165.

Islami, F., Pourshams, A., Nasrollahzadeh, D., Kamangar, F., Fahimi, S., Shakeri, R., Abedi-Ardekani, B., Merat, S., Vahedi, H., Semnani, S., Abnet, C. C., Brennan, P., Moller, H., Saidi, F., Dawsey, S. M., Malekzadeh, R., and Boffetta, P. (2009c). Tea drinking habits and oesophageal cancer in a high risk area in northern Iran: population based case-control study. BMJ 338, b929.

Jemal, A., Bray, F., Center, M. M., Ferlay, J., Ward, E., and Forman, D. (2011). Global cancer statistics. CA Cancer J. Clin. 61, 69-90.

Joint Iran-IARC Study Group. (1977). Esophageal cancer studies in the Caspian littoral of Iran: results of population studies - a prodrome. Joint Iran-International Agency for Research on Cancer Study Group. J. Natl. Cancer Inst. 59, 1127-1138.

Kamangar, F., Chow, W. H., Abnet, C. C., and Dawsey, S. M. (2009). Environmental causes of esophageal cancer. Gastroenterol. Clin. North Am. 38, 27-57, vii.

Kamangar, F., Strickland, P. T., Pourshams, A., Malekzadeh, R., Boffetta, P., Roth, M. J., Abnet, C. C., Saadatian-Elahi, M., Rakhshani, N., Brennan, P., Etemadi, A., and Dawsey, S. M. (2005). High exposure to polycyclic aromatic hydrocarbons may contribute to high risk of esophageal cancer in northeastern Iran. Anticancer Res. 25, 425-428.

Kang, D., Rothman, N., Cho, S. H., Lim, H. S., Kwon, H. J., Kim, S M., Schwartz, B., and Strickland, P. T. (1995). Association of exposure to polycyclic aromatic hydrocarbons (estimated from job category) with concentration of 1-hydroxypyrene glucuronide in urine from workers at a steel plant. Occup. Environ. Med. 52, 593-599.

Ketelslegers, H. B., Gottschalk, R. W. Godschalk, R. W., Knaapen, A. M., van Schooten, F. J., Vlietinck, R. F., Kleinjans, J. C., and Van Delft, J. H. (2006). Interindividual variations in DNA adduct levels assessed by analysis of multiple genetic polymorphisms in smokers. Cancer Epidemiol. Biomarkers Prev. 15, 624-629.

Knaapen, A. M., Ketelslegers, H. B. Gottschalk, R. W., Janssen, R. G. Paulussen, A. D., Smeets, H. J., Godschalk, R. W., van Schooten, F. J., Kleinjans, J. C., and Van Delft, J. H. (2004). Simultaneous genotyping of nine polymorphisms in xenobioticmetabolizing enzymes by multiplex PCR amplification and single base extension. Clin. Chem. 50, 1664-1668.

Lai, C. H., Liou, S. H., Lin, H. C. Shih, T. S., Tsai, P. J., Chen, J. S., Yang, T., Jaakkola, J. J., and Strickland, P. T. (2005). Exposure to traffic exhausts and oxidative DNA damage. Occup. Environ. Med. 62, 216-222.

Langie, S. A., Wilms, L. C., Hamalainen, S., Kleinjans, J. C., Godschalk, R. W. and van Schooten, F. J. (2010). Modulation of nucleotide excision repair in human lymphocytes by genetic and dietary factors. Br. J. Nutr. 103, 490-501.

Lee, J., Kang, D., Lee, K. H., Ichiba, M. Zhang, J., Tomokuni, K., Hwang, E. S., Park, C. G., Ha, M., Kim, S., Han, S. B., Choi, J. W., Lee, E., Jang, J. Y., Strickland, P. T., Hirvonen, A., and Cho, S. H. (2002). Influence of GSTM1 genotype on association between aromatic DNA adducts and urinary PAH metabolites in incineration workers. Mutat. Res. 514, 213-221.

Lee, K. H., Ichiba, M., Zhang, J., Tomokuni, K., Hong, Y. C., Ha, M., Kwon, H. J., Koh, S. B., Choi, H. R., Lee, K. H., Park, C. G., Cho, S. H., Hirvonen, A., Strickland, P. T., Vermeulen, R., Hayes, R. B., and Kang, D. (2003). Multiple biomarkers study in painters in a shipyard in Korea. Mutat. Res. 540, 89-98.
Mahboubi, E. (1971). Epidemiologic study of esophageal carcinoma in Iran. Int. Surg. 56, 68-71.

Mahboubi, E., Kmet, J., Cook, P. J. Day, N. E., Ghadirian, P., and Salmasizadeh, S. (1973). Oesophageal cancer studies in the Caspian Littoral of Iran: the Caspian cancer registry. $\mathrm{Br}$. J. Cancer 28, 197-214.

Perello, G., Marti-Cid, R., Castell, V., Llobet, J. M., and Domingo, J. L. (2008). Concentrations of polybrominated diphenyl ethers, hexachlorobenzene and polycyclic aromatic hydrocarbons in various foodstuffs before and after cooking. Food Chem. Toxicol. 47, 709-715.

Petchpoung, K., Kaojarern, S., Yoovathaworn, K., Sura, T., and Sirivarasai, J. (2011). The influence of metabolic gene polymorphisms on urinary 1-hydroxypyrene concentration in Thai bus drivers. Environ. Toxicol. Pharmacol. 31, 160-164.

Pourshams, A., Khademi, H., Malekshah, A. F., Islami, F., Nouraei, M., Sadjadi, A. R., Jafari, E., Rakhshani, N., Salahi, R., Semnani, S., Kamangar, F., Abnet, C. C., Ponder, B., Day, N., Dawsey, S. M., Boffetta, P., and Malekzadeh, R. (2010). Cohort Profile: The Golestan Cohort Study a prospective study of oesophageal cancer in northern Iran. Int. J. Epidemiol. 39, 52-59.

Ramos, K. S., and Moorthy, B. (2005). Bioactivation of polycyclic aromatic hydrocarbon carcinogens within the vascular wall: implications for human atherogenesis. Drug Metab. Rev. 37, 595-610.

Roth, M. J., Guo-Qing, W., Lewin, K. J., Ning, L., Dawsey, S. M., Wesley, M. N., Giffen, C., Yong-Qiang, X., Maher, M. M., and Taylor, P. R. (1998a). Histopathologic changes seen in esophagectomy specimens from the high-risk region of Linxian, China: potential clues to an etiologic exposure? Hum. Pathol. 29, 1294-1298.

Roth, M. J., Strickland, K. L., Wang, G. Q., Rothman, N., Greenberg, A., and Dawsey, S. M. (1998b). High levels of carcinogenic polycyclic aromatic hydrocarbons present within food from Linxian, China may contribute to that region's high incidence of oesophageal cancer. Eur. J. Cancer 34, 757-758.

Roth, M. J., Qiao, Y. L., Rothman, N., Tangrea, J. A., Dawsey, S. M., Wang, G. Q., Cho, S. H., Kang, D., Taylor, P. R., and Strickland, P. T. (2001). High urine 1-hydroxypyrene glucuronide concentrations in Linxian, China, 
an area of high risk for squamous oesophageal cancer. Biomarkers 6, 381-386.

Scherer, G., Conze, C., Tricker, A. R., and Adlkofer, F. (1992). Uptake of tobacco smoke constituents on exposure to environmental tobacco smoke (ETS). Clin. Investig. 70, 352-367.

Schoket, B., Papp, G., Levay, K., Mrackova, G., Kadlubar, F. F., and Vincze, I. (2001). Impact of metabolic genotypes on levels of biomarkers of genotoxic exposure. Mutat. Res. 482, 57-69.

Semnani, S., Sadjadi, A., Fahimi, S., Nouraie, M., Naeimi, M., Kabir, J., Fakheri, H., Saadatnia, H., Ghavamnasiri, M. R., and Malekzadeh, R. (2006). Declining incidence of esophageal cancer in the Turkmen Plain, eastern part of the Caspian Littoral of Iran: a retrospective cancer surveillance. Cancer Detect. Prev. 30, 14-19.

Straif, K., Baan, R., Grosse, Y., Secretan, B., El Ghissassi, F., and Cogliano, V. (2005). Carcinogenicity of polycyclic aromatic hydrocarbons. Lancet Oncol. 6, 931-932.
Strickland, P., Kang, D., and Sithisarankul, P. (1996). Polycyclic aromatic hydrocarbon metabolites in urine as biomarkers of exposure and effect. Environ. Health Perspect. 104(Suppl. 5), 927-932.

Strickland, P. T., Kang, D., Bowman, E. D., Fitzwilliam, A., Downing, T. E., Rothman, N., Groopman, J. D., and Weston, A. (1994). Identification of 1-hydroxypyrene glucuronide as a major pyrene metabolite in human urine by synchronous fluorescence spectroscopy and gas chromatography-mass spectrometry. Carcinogenesis 15, 483-487.

Suwan-Ampai, P., Navas-Acien, A., Strickland, P. T., and Agnew, J. (2009). Involuntary tobacco smoke exposure and urinary levels of polycyclic aromatic hydrocarbons in the United States, 1999 to 2002. Cancer Epidemiol. Biomarkers Prev. 18, 884-893.

Unwin, J., Cocker, J., Scobbie, E., and Chambers, H. (2006). An assessment of occupational exposure to polycyclic aromatic hydrocarbons in the UK. Ann. Occup. Hyg. 50, 395-403.
Vineis, P., Talaska, G., Malaveille, C. Bartsch, H., Martone, T., Sithisarankul, P., and Strickland, P. (1996). DNA adducts in urothelial cells: relationship with biomarkers of exposure to arylamines and polycyclic aromatic hydrocarbons from tobacco smoke. Int. J. Cancer 65 314-316.

Wornat, M. J., Ledesma, E. B., Sandrowitz, A. K., Roth, M. J., Dawsey, S. M., Qiao, Y. L., and Chen, W. (2001). Polycyclic aromatic hydrocarbons identified in soot extracts from domestic coalburning stoves of Henan Province, China. Environ. Sci. Technol. 35, 1943-1952.

Conflict of Interest Statement: The authors declare that the research was conducted in the absence of any commercial or financial relationships that could be construed as a potential conflict of interest.

Received: 17 October 2011; accepted: 29 January 2012; published online: 17 February 2012.
Citation: Islami $F$, Boffetta $P$, van Schooten FJ, Strickland P, Phillips DH, Pourshams A, Fazel-Tabar Malekshah A, Godschalk R, Jafari E, Etemadi A, Abubaker S, Kamangar F, Straif $K$, Møller H, Schüz J and Malekzadeh $R$ (2012) Exposure to polycyclic aromatic hydrocarbons among never smokers in Golestan Province, Iran, an area of high incidence of esophageal cancer-a cross-sectional study with repeated measurement of urinary 1-OHPG in two seasons. Front. Oncol. 2:14. doi: 10.3389/fonc. 2012.00014

This article was submitted to Frontiers in Cancer Epidemiology and Prevention, a specialty of Frontiers in Oncology. Copyright (c) 2012 Islami, Boffetta, van Schooten, Strickland, Phillips, Pourshams, Fazel-Tabar Malekshah, Godschalk, Jafari, Etemadi, Abubaker, Kamangar, Straif, Møller, Schüz and Malekzadeh. This is an open-access article distributed under the terms of the Creative Commons Attribution Non Commercial License, which permits non-commercial use, distribution, and reproduction in other forums, provided the original authors and source are credited. 


\section{APPENDIX \\ DETAILS OF LABORATORY ASSESSMENTS \\ Assessment of 1-hydroxypyrene glucuronide (1-OHPG)}

In order to hydrolyze acid-labile conjugated metabolites, each urine sample was treated with $1 \mathrm{~N} \mathrm{HCl}$ at $90^{\circ} \mathrm{C}$ for $1 \mathrm{~h}$. Under these hydrolysis conditions, 1-OHPG is stable. Then, 1-OHPG was loaded on methanol/water primed Sep-Pak C18 cartridges (Waters, Milford, MA, USA). After being washed with water and $30 \%$ methanol in water, the samples were eluted by the same volume of $80 \%$ methanol in water. With mild heating under vacuum, the eluate was concentrated to approximately one-eighth of the initial volume. Adding $7.5 \mathrm{mM}$ phosphate-buffered saline (PBS), with $\mathrm{pH}$ 7.4, the volume was increased to $4 \mathrm{ml}$. The samples were loaded on immunoaffinity columns containing $\mathrm{CNBr}$-activated Sepharose $4 \mathrm{~B}$ conjugated with monoclonal antibody $8 \mathrm{E} 11$ which recognizes 1-OHPG. Then the samples were washed with $7.5 \mathrm{mM}$ PBS and 25\% methanol in 7.5 mM PBS, and 1-OHPG was eluted with $70 \%$ methanol in $7.5 \mathrm{mM}$ PBS. The samples were dried and re-dissolved in $2 \mathrm{ml}$ of water. The 1-OHPG content of the samples was measured with synchronous fluorescence spectroscopy (Perkin Elmer LS50B Luminescence spectrometer, Norwalk, CT, USA) using a wavelength difference of $34 \mathrm{~nm}$ between excitation and emission. The limit of detection was $0.01 \mathrm{ng} 1-\mathrm{OHPG} / \mathrm{ml}$ urine and the recovery of the assay was $95-100 \%$. The adjustment of 1-OHPG levels for creatinine was done as following:

$$
\begin{aligned}
& \text { Creatinine }(\mathrm{mg} / \mathrm{dl}) \times 0.0884=\text { creatinine }(\mu \mathrm{mol} / \mathrm{ml}) \\
& \mathrm{Cr} \text { - adjusted } 1-\text { OHPG }(\mathrm{mol} / \mathrm{molCr})=1-\text { OHPG }(\mathrm{pmol} / \mathrm{ml}) / \\
& \text { creatinine }(\mu \mathrm{mol} / \mathrm{ml})
\end{aligned}
$$

\section{Genotyping}

DNA was isolated by standard phenol extraction procedures and PCR was done as reported previously(Knaapen et al., 2004) in two multiplex PCR reactions. The multiplexes included the following polymorphisms; series A: CYP1A203 (rs762551), NAT2-02 (rs1799931), NAT2-06 (rs1801280), NAT2-08 (rs1799930), GSTM1-02 (deletion), GSTP1-01 (rs1695), GSTP1-02 (rs1138272), and GSTT1-02 (deletion); series B: CYP1A1-01 (rs1048943), CYP1A1-03 (rs1799814), CYP1B1-05 (rs1056836), CYP1B1-07 (rs1800440), CYP2E1-05 (rs6413420), CYP3A4-02 (rs2740574), and MPO-02 (rs2333227). PCR was carried out in a Tgradient 96-well Thermal cycler (Biometra, Goettingen, Germany) in a $10-\mu$ l volume, containing PCR buffer (Invitrogen, Breda, the Netherlands), $0.2 \mathrm{mmol} / \mathrm{l}$ deoxynucleotide triphosphates (Invitrogen), $1.75 \mathrm{mmol} / \mathrm{l} \mathrm{MgCl}_{2}$ (Invitrogen), 0.25 unit Platinum Taq-Polymerase (Invitrogen), and $40 \mathrm{ng}$ template DNA. The final concentration of the primers was $0.2 \mu \mathrm{mol} / \mathrm{l}$. PCR conditions were: denaturation at $94^{\circ} \mathrm{C}$ for $3 \mathrm{~min} ; 30$ cycles of $94^{\circ} \mathrm{C}$ for $30 \mathrm{~s}, 56^{\circ} \mathrm{C}$ (series A) $/ 60^{\circ} \mathrm{C}$ (series B) for $30 \mathrm{~s}$, and $72^{\circ} \mathrm{C}$ for $30 \mathrm{~s}$; and a final extension at $72^{\circ} \mathrm{C}$ for $5 \mathrm{~min}$. The samples were incubated at $37^{\circ} \mathrm{C}(45 \mathrm{~min})$ with $4 \mu \mathrm{l}$ Exo-SAP-IT (Amersham, Roosendaal, the Netherlands) to degrade deoxynucleotide triphosphates and PCR primers. The enzymes were deactivated at $75^{\circ} \mathrm{C}(15 \mathrm{~min})$.

Genotyping was performed by single base extension (SBE) method using SnaPShot (Applied Biosystems, Nieuwerkerk, a.d. IJssel, the Netherlands), and primer 3 and Netprimer software were used to design SBE primers. Following SBE, the samples were incubated at $37^{\circ} \mathrm{C}(1 \mathrm{~h})$ with 1 unit shrimp alkaline phosphatase (Amersham) to degrade the unincorporated dideoxynucleotide triphosphates. Two multiplex genotyping experiments (as described above) were used for SBE reactions. SBE products were diluted and mixed with deionized formamide containing Genescan $120 \mathrm{LIZ}$ size standard. The mixture was denatured at $95^{\circ} \mathrm{C}$ for 5 min. Finally, the samples were analyzed on an ABI Prism 3100 genetic analyser using Genescan Analysis software. 